\title{
Metrology for humidity at high temperatures and transient conditions
}

\author{
Heinonen $M^{1, a}$, Cavallarin $L^{2}$, Dell'lsola $M^{3}$, Ebert $V^{4}$, Fernicola $V^{5}$, Georgin $E^{6}$, Hudoklin $D^{7}$, Nielsen $J^{8}$, Østergaard $P F^{8}$, \\ Peruzzi $A^{9}$, Pietari $\mathrm{T}^{10}$, Wagner $\mathrm{S}^{11}$ and Werhahn $\mathrm{O}^{4}$ \\ ${ }^{1}$ Centre for Metrology MIKES, VTT Technical Research Centre of Finland Ltd, P.O. Box 1000, FI-02044 VTT, Finland \\ ${ }^{2}$ Istituto di Scienze delle Produzioni Alimentari CNR, Largo Braccini, 2, 10095 Grugliasco, Italy \\ ${ }^{3}$ Università degli Studi di Cassino e del Lazio Meridionale, Via G. Di Biasio 43, 03043 Cassino, Italy \\ ${ }^{4}$ Physikalisch-Technische Bundesanstalt, Bundesallee 100, 38112 Braunschweig, Germany \\ ${ }^{5}$ Istituto Nazionale di Ricerca Metrologica, Strada delle Cacce 91, 10135 Torino, Italy \\ ${ }^{6}$ LNE-CETIAT, 25 avenue des arts - BP 52042, 69603 Villeurbanne, France \\ ${ }^{7}$ University of Ljubljana, Faculty of Electrical Engineering, Tržaška 25, 1000 Ljubljana, Slovenia \\ ${ }^{8}$ Danish Technological Institute, Kongsvang Allé 29, DK-8000 Aarhus C., Denmark \\ ${ }^{9}$ VSL, P.O.Box 654, 2600 AR Delft, Netherlands \\ ${ }^{10}$ Vaisala Oyj, Vanha Nurmijärventie 21, 01670 Vantaa, Finland \\ ${ }^{11}$ Technische Universität Darmstadt, HTPD, Jovanka-Bontschits-Str. 2, 64287 Darmstadt, Germany
}

\begin{abstract}
Résumé. Les hygromètres sont largement mis en œuvre pour des conditions de température supérieures à $100^{\circ} \mathrm{C}$ et dans des conditions de régimes dynamiques. Cependant, la plupart des laboratoires européens ne peuvent fournir d'étalonnages qu'à des températures relativement basses et dans des conditions de régimes établi et stables. Il apparaît donc nécessaire de développer de nouvelles techniques et méthodes d'étalonnage de sorte à élargir la gamme des possibilités d'étalonnage et de garantir ainsi une traçabilité qui soit en adéquation avec les besoins industriels. Ces développements sont d'autant plus importants vis-à-vis des besoins de mesure à hautes températures, en régimes dynamiques et pour les mesures d'activité de l'eau. Les conditions de mesures d'humidité en régimes transitoires et dynamiques sont une composante à part entière des environnements industriels d'essai et de test et il n'existe actuellement aucune méthode permettant l'estimation d'incertitudes dans de telles situations. Cet article met en avant un nouveau projet européen de recherche en métrologie - HIT: "Metrology for Humidity at high Temperature and Transient conditions". Ce projet a été construit de sorte à améliorer significativement l'exactitude des mesures d'humidité jusqu'à des températures de $180^{\circ} \mathrm{C}$ et en régimes dynamiques en contexte industriel, au travers de l'amélioration des techniques de mesure et d'étalonnage. Les principaux bénfices que doit apporter ce projet, sont l'extension des gammes d'étalonnages industriels à haute température et en régimes dynamiques, l'établissement de nouvelles méthodes de mesure d'humidité en régime dynamique et en présence de variations spatiales ainsi que le développement de nouvelles méthodes de mesure d'activité de l'eau "en ligne" sur les procédés industriels. L'ensemble de ces développements seront validés et illustrés au travers d'applications industrielles.
\end{abstract}

\section{Introduction}

Drying is estimated to cost European industry around 30 $000 \mathrm{M} €$ per year in associated energy costs [1-2]. Every $0.1 \%$ improvement in drying efficiency due to better process control could save around $30 \mathrm{M} € /$ year.
Monitoring humidity under transient conditions and at temperatures above $100{ }^{\circ} \mathrm{C}$ is a key factor in controlling drying processes. Thus, by improving the reliability of these humidity measurements annual savings of millions of euros can be achieved in Europe.

\footnotetext{
${ }^{\mathrm{a}}$ Corresponding author: martti.heinonen@vtt.fi
} 
The quality and shelf life of pharmaceutical products are significantly affected by the humidity of the ambient air during manufacturing and storage. Pharmaceutical companies allocate significant resources in order to maintain high quality monitoring of humidity in their production premises and storage facilities. These companies are therefore seeking more efficient calibration methods for humidity sensors and improved methods for spatial humidity monitoring under transient conditions to achieve savings both in costs and materials.

The food industry is the second largest manufacturing sector in the EU with a total manufacturing turnover of over 900 billion euros [3]. Drying and baking are key processes in this sector, and water activity is a key parameter in controlling the quality of food and feed products. In order to determine water activity, material samples are taken from the process and measured using laboratory analysers. A significant quantity of material is wasted because of slow feedback, and the optimisation of energy consumption is limited by the larger safety margins that are required due to uncertainties which are increased by sampling errors and transient conditions.

More than 180 accredited industrial laboratories in Europe calibrate hygrometers [4] for their customers but none of them can perform calibrations at temperatures above $100{ }^{\circ} \mathrm{C}$ or under transient conditions because appropriate methods and techniques are not available. Furthermore, there is no measurement technology available for monitoring fast humidity transients at temperatures above $100{ }^{\circ} \mathrm{C}$. Dynamic humidity measurements are an integral part of the environmental tests for various industrial products but no proper methods exist to estimate their uncertainty.

This paper outlines the research to be carried out within the HIT project (14IND11 "Metrology for Humidity at High Temperatures and Transient conditions") that was selected to be funded in the Call 2014 - Industry of the European Metrology Programme for Innovation and Research (EMPIR).

\section{Objectives of the research}

There are five main objectives in this research:

1. To develop humidity calibration methods and procedures for industrial use for air temperatures above $100{ }^{\circ} \mathrm{C}$ and absolute pressures from 0.5 to 6 bar. The uncertainty levels appropriate for relevant applications (typically less than $2 \%$ rh) will be achieved with the minimum additional work load and equipment costs.

2. To develop humidity calibration methods and procedures for industrial use applicable to transient conditions. The same uncertainty level should be achieved as when performed under steady state conditions but the time needed for the calibration will be shorter by at least $50 \%$.
3. To develop humidity measurement techniques and procedures for the accurate monitoring of temporal and spatial humidity variations in selected applications. The applications include monitoring fast humidity transients in process environments with temperatures up to $180{ }^{\circ} \mathrm{C}$ and detection of the influence of microbiological processes on the transient humidity conditions within small samples. The target relative uncertainty for the water vapour amount fraction at high temperatures is $5 \%$, and the uncertainty for the relative humidity measurements will be less than $2 \%$ rh.

4. To develop water activity measurement techniques for in-line measurement applications - with a measurement uncertainty smaller than 0.02 - and to develop methods for establishing the traceability link between water activity and water mass fraction measurements including the development of tools for analysing error sources in water activity measurements which are an integral part of sorption isotherm measurements.

\section{Implementation of the project}

The research will be carried out in a project starting in September 2015 and ending 2018 by 15 partner organisations. The work is carried out in three technical work packages while two other work packages are for creating impact and managing the project.

\subsection{Project partners}

To achieve the ambitious objectives of the project, a versatile group of metrology institutes, universities and industrial companies bring their expertise to this research consortium. As shown in Table 1, four partners are industrial companies and eight partners are national metrology institutes

In addition, several companies and research institutes will contribute to the research as official collaborators.

\subsection{Organisation}

The work package 1 will result the targeted advancements in calibration methods, i.e. the objectives 1 and 2. New measurement methods for humidity transients and water activity will be developed in the work package 2 . The developments of these two work packages will be demonstrated in industrial applications within the work package 3 . To achieve significant improvement in the accuracy of industrial humidity measurements at high temperatures up to $180{ }^{\circ} \mathrm{C}$ and transient conditions the consortium will prepare guidelines and organise trainings, feed input to relevant the standardisation committees, collaborate with industrial stakeholders and 
publish results in various media within the work package

4. The organisation is summarised in Figure 1.
Figure 1. Organisation of the HIT project.

\subsection{Methods}

\subsubsection{Development of new calibration methods}

Various relative humidity sensors will be tested in static conditions in the temperature range up to $180^{\circ} \mathrm{C}$. Results of these tests will enable us to identify most practical calibration methods and procedures for use in industrial calibration laboratories. Aspects to be considered are validity of calibration results to measurement conditions, amount of additional work due to the extended temperature range and cost of investment to calibration equipment. To ensure SI traceability in the full range of temperature (up to $180{ }^{\circ} \mathrm{C}$ ) and pressure (up to 6 bar), a new mass fraction vapour/steam generator will be developed.

To improve the applicability of calibration results to humidity measurements in transient conditions, new calibration procedures based on dynamic measurements will be studied using various humidity sensors. Application of dynamic measurements to improve the efficiency in calibration will also be studied and demonstrated by developing a new field humidity calibrator.

The humidity instruments to be used in the development of the calibration methods will include several types of impedance sensors, acoustic sensors and a laser spectroscopic hygrometer.

\subsubsection{Improved measurement methods}

To provide a reliable transfer standard for high temperature and transient humidity conditions, a new direct Tunable Diode Laser Absorption Spectroscopic (dTDLAS) hygrometer will be developed. Its response time will be well below $1 \mathrm{~s}$.

A new approach will be developed for detecting the influence of microbiological processes on the transient humidity conditions within sterile petri dish samples stacked in a large climatic room. The new method will meet requirements of sterile environments and provide high spatial resolution. The measurement uncertainty will be better than $2 \%$ rh.

For improving cost efficiency and product quality in food and feed processing, a reliable method for inline determination of water activity in the industry will be developed for the first time. This novel method will comprise traceable continuous temperature and samplebased sorption isotherm measurements and appropriate new simulation tools. The target uncertainty is smaller than 0.02 .

\subsubsection{Demonstration in industry}

The applicability of the methods and measurement techniques developed in WP2 to selected industrial applications and the benefits provided by the improved humidity calibration techniques developed in WP1 will 
be demonstrated in food, paper and pharmaceuticals production.

In selected food and paper processing applications we will demonstrate the effect of traceable humidity measurements at high temperature (between $100{ }^{\circ} \mathrm{C}$ and $180{ }^{\circ} \mathrm{C}$ ) on process tuning and optimisation. The effectiveness of the methods will be validated by a direct assessment of improved final food product quality.

The new methods for measuring humidity within sterile dish samples, calibrating humidity sensors applying dynamic measurements and measuring water activity in line will be implemented and demonstrated in drug manufacturing and food processing.

\section{Outcomes of the project}

The HIT project will deliver new and improved methods and techniques for humidity measurement and monitoring at high temperatures and under transient conditions. These advancements will enable a wide range of industrial enterprises to enhance their competitiveness through reduced energy consumption and waste production and through more efficient and reliable quality assurance and new products. The outcomes will be broadly exploited by the industrial partners, manufacturing industry, industrial test and calibration service providers, instrument manufacturers and the wider stakeholder community.

The results will be made widely available through scientific publications, technical reports and a good practice guide. A EURAMET guide will be prepared on calibration and uncertainty in humidity measurements at temperatures above $100{ }^{\circ} \mathrm{C}$ and in transient conditions. New measurement, calibration and test services will be launched by the partners.

The results will also be disseminated through project a website, workshops, training courses, articles in various media and liaison with working groups of standardisation, industry and metrology.

\section{Summary}

A new European metrology research project - HIT: "Metrology for Humidity at High Temperatures and Transient conditions" has been set up to improve industrial humidity measurements at high temperatures up to $180{ }^{\circ} \mathrm{C}$ and transient conditions. This will be achieved by developing improved measurement and calibration techniques for enabling and/or strengthening SI traceability. The project will result in feasible means to extend industrial humidity calibrations to high temperatures and transient conditions, new measurement methods for transient humidity conditions and spatial variations and a novel method for measuring water activity in line. Demonstrations in industrial applications will show the applicability of the developments.
This work is funded by the EMPIR initiative that is cofunded by the European Union's Horizon 2020 research and innovation programme and the EMPIR Participating States.

\section{References}

1. EUROSTAT; http://epp.eurostat.ec.europa.eu

2. Ian C. Kemp: Fundamentals of Energy Analysis of Dryers, in: E. Tsotsas and A. S. Mujumdar (eds.), Modern Drying Technology Volume 4: Energy Savings, First Edition, 2012 Wiley-VCH Verlag $\mathrm{GmbH}$

3. European Industry in a Changing World, Updated Sectorial Overview, EU Commission staff working document SEC(2009) 1111

4. www.european-accreditation.or

\section{Acknowledgements}

